\title{
Filtered Leakage Current Measurement for Various Loads
}

\author{
Erwin Sutanto ${ }^{1}$, Silvi Nurwahyuni², Riky Tri Yunardi², Guillermo Escrivá-Escrivá ${ }^{3}$ \\ ${ }^{1}$ Biomedical Engineering, Faculty of Science and Technology, Universitas Airlangga, Kampus C, Jalan \\ Mulyosari, Surabaya60115, Indonesia \\ ${ }^{2}$ Department of Engineering, Faculty of Vocational, Universitas Airlangga, Campus B, Jalan Srikana 65, \\ Surabaya 60286, Indonesia \\ ${ }^{3}$ Institute for Energy Engineering, Universitat Politècnica de València, Camino de Vera, $s / n$, Edificio $8 E$, \\ escalera F, 2 opiso, 46022 Valencia, Spain
}

\begin{abstract}
Thepurpose of this study was to determine the link between induction voltages from various electrical loads. We used a residual current device (RCD) circuit that operates with a capacitor as a DC voltage reading tool. The circuit reads the value of the leakage current generated by the sensing coil from the RCD. It also uses the Blynk framework as an online monitoring system and a WeMos D1-R2 microcontroller to connect to the server using Wi-Fi. Using this system, the dataset was collected in a Python server and utilized with a machine learning technique to draw a correlation between the load power and reading voltage. This will help improve the mistakes of a common RCD cut-off point, which is usually defined only at a specific induced voltage. For the different types, an LED lamp and typical electric fan were used as loads in the experiment. Meanwhile, for a similar type of load, three different LED lamps were characterized using machine learning to show the correlation. From the comparison, a threshold voltage of around $1 \mathrm{~V}$ and three different gradients with increases of more than $10 \%$ are found for LED lamps with loads of $3 \mathrm{~W}, 5 \mathrm{~W}$, and $9 \mathrm{~W}$.The results show that the relationship depends on the type of its power supply.
\end{abstract}

Keywords: Circuit breaker; Electrical loads; Filtered signal; Leakage current; Machine learning

\section{Introduction}

In our modern daily activities, it is undeniable that we depend on electronic devices. With the technological advances that are rapidly being developed, it is easy to use electrical utilities. It may start with a refrigerator for food storage and a rice cooker as a cooking helper; we may then add an air conditioner as a room temperature controller, and finally, a digital television (TV) for entertainment. There are many other common devices that may be included in the long list of our electrical utilities. However, there may be leakage currents from those electrical loads that we are unaware of. The current could flow in the unarranged path of our electrical wiring, for example, through poor electrical insulation or ungrounded chassis (Lee and Lin, 2005). This may be due to the changed value of capacitance against the alternating voltage or the lifespan of the installation.

The measurement of electrical devices could be useful in determining the possible danger of household electricity. This measurement can be conducted using technologies, such as the Internet of Things (IoT) and machine learning, as in concentrations

${ }^{*}$ Corresponding author's email: erwin_sutanto@fst.unair.ac.id, Tel.: +62-31-5936501; Fax: +62-31-5936502 doi: 10.14716/ijtech.v12i2.4302 
measurement (Chong et al., 2016). The concept of a system includes three main elements.

Specifically, physical objects are integrated with a sensor module, internet connection, and data center using a server to store information from the measurement (Muhammad Asraf et al., 2018). In this case, the measured object is the leakage current, which is measured using a capacitor as a filter circuit (Sutanto et al., 2019). The connectivity through the internet uses a common Blynk IoT framework, as in Sutanto et al. (2020). Finally, the server as data storage is based on Python, which will also be useful for analysis of the data, for example, using TensorFlow (Piponi et al., 2020).

Machine learning could be seen as a tool in computers that allows them to learn without requiring an explanation or being explicitly programmed, as they are in normal software development. Thus, in this study, machine learning is used to learn the leakage current behavior from the residual current device (RCD). This could help us develop a system capable of identifying the possible function in responding to the leakage current using only the induction voltage. Meanwhile, the model training requires datasets before giving out a prediction model that best fits the system. This kind of application is usually applicable in a specific domain and cannot be applied to all possibilities (Shukla, 2018). Similarly, the results of this work will be used only to identify leakage currents from specific electrical loads.

In this work, the approach is applied to Light-Emitting Diode (LED) based lamps in comparison with Compact Fluorescent Lamp(CFL), as done in Latief et al. (2019), because of the low cost of these lamps. We start by describing a filter design for the RCD before outlining our monitoring system with the discussed IoT system and Python server. The system is evaluated with different kinds of loads by comparing the LED lamp and electric fan. It is also tested with different loads using three different wattages of LED lamps.

\section{Methods}

The main characteristic of the measurement comes from the filter as signal processing block. Thus, we need to analyze the filter design in relation to the possible filter designs, such as a specific band pass filter (Zulkifli, 2014; Wibisono, 2014). Then, it is the target system that is used for comparing the leakage currents from various power loads. The system consists of hardware and software with IoT module as hardware part and machine learning as in software part.

\subsection{Induction Voltage Filter}

The design of the measurement circuit accommodates the leakage current measurement into a digital microcontroller. From there, the decision to cut off the electricity is no longer made by the RCD circuit but depends on the embedded logic inside the microcontroller. To realize this, the leakage current detection system uses a kind of filter (Sutanto et al., 2019). The RCD core intercepts the electricity power line using two coils. Then, a sensing coil that will read the magnetic induction is connected to the filter. The filter is designed to rectify the signal into a DC signal. This is useful for overcoming the irregular waveform that will be read by the sensing coil. This design starts with a rectifier circuit using a diode bridge to be first converted as a full wave rectifier. It then stabilizes the voltage using a capacitor. Finally, a Zener diode is used as a voltage limiter before being connected to WeMos D1-R2 with 3.3V as the maximum input voltage (Bohora et al., 2016). The complete circuit is shown in Figure 1.

The signal coming out of the diode bridge is a positive full waveform. It is formed by following the characteristics of the capacitor as described in Gupta and Sharma (2019). Using Laplace transform, the signal can be written as in Equation 1. 


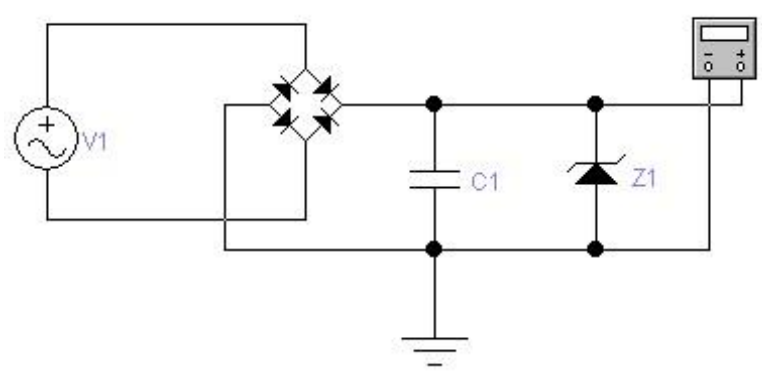

Figure 1 Filter design

$$
V_{\text {measured }}=X_{c} \cdot I_{1}=\frac{I_{1}}{s \cdot C_{1}}=\frac{I_{1}}{2 \cdot \pi \cdot f \cdot C_{1}}
$$

where $V_{\text {measured }}$ is the formed induction voltage in responding to the capacitor, $X_{c}$ is the capacitive reactance from the circuit, and $I_{1}$ is the current flow in the $C_{1}$. In addition, $\mathrm{s}$ is the parameter for the s-domain. Finally, $C_{1}$ is the capacitor value. The other parameters are common symbols, such as $\pi$ for a constant value of 3.14 and f for the frequency of the AC signal. Overall, this formed signal over the circuit is based on the frequency of the changing value of Ileakage. How the capacitor stabilizes the AC signalis observed using an oscilloscope, as described below. Meanwhile, $V_{1}$ is the induction voltage coming out of the RCD:

$$
V_{1}=-\frac{d \phi_{B}}{d t}=-A \frac{d}{d t}\left(\frac{\mu_{r} \cdot N}{\theta \cdot r} I_{\text {leakage }} \cos (\omega t)\right)
$$

Equation 2 is the physics formula that defines the induction voltage. Here, $\varphi_{\text {в }}$ is the magnetic flux, which is strengthened inside the RCD core. Moreover, $A$ is the width of the RCD core, $\mu_{r}$ is the relative permeability material of the core, $N$ is the number of windings along the RCD, and Ileakage is the leakage current. With this equation, we can see that there is a relationship between the induction voltage and the leakage current that can be measured.

\subsection{Leakage Current Monitoring}

By incorporating the IoT module as a connection, there is a possibility of monitoring leakage current of the electrical system. The system can monitor more than one electrical utility. It keeps a list of leakage currents from all the devices in real time. Figure 2 shows a possible application of the system.

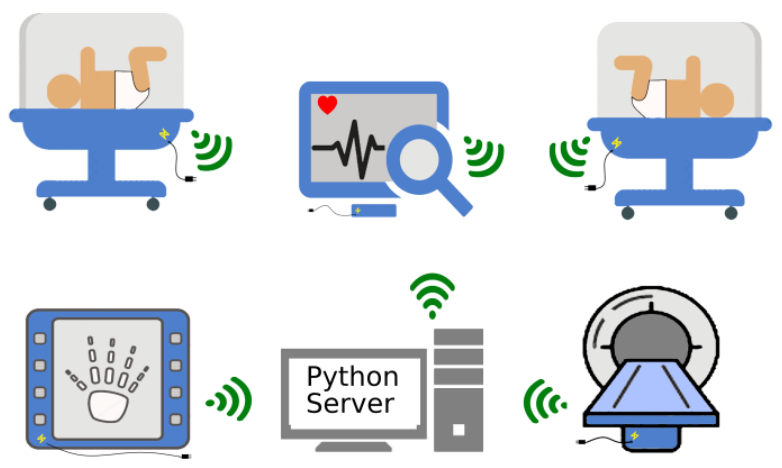

Figure 2 System design

The figure gives an example of an application where the system is used in hospital. In the hospital context, it could be used to monitor common medical devices, such as X-ray 
equipment, infant incubators, electrocardiograph (ECG) machines, and magnetic resonance imaging (MRI) equipment. In general, if a piece of equipment uses electricity, then its electricity use may need to be measured. However, if we look at this issue in detail, these devices have differences in their power consumptions. Each of them should have electrical specifications. These specifications are normally attached to the back side of the device using a plate or eye-catching sticker. Usually, the specifications will include the allowed range of electrical input. This can comprise the voltage; type of current, AC or DC; and the possible maximum current drawn from the device (Roy Chowdhury et al., 2019). Sometimes, they will also include the device's power consumption. There may be differences in outlining the specifications among devices, which can be due to the possibility of obtaining one value such as power from other values like current by following Ohm's Law, which is as follows:

$$
P_{\text {load }}=I^{2} R_{\text {load }}=\left(\frac{V}{R_{\text {load }}}\right)^{2} \cdot R=\frac{V^{2}}{R_{\text {load }}}
$$

With $I$ as the current flow to the device and $R_{\text {load }}$ as the load resistance of the device, it is possible to obtain $P_{\text {load }}$ as the power consumption. Alternatively, if we know the value of $V$ as voltage input and $R$, it is possible to calculate the power. These electrical parameters can be used as indicators of the load. However, we use power as the main indicator of these loads.

The leakage current cannot be identified using the electrical specifications described above. This may depend on how the electricity is used as the power supply inside the device. For example, we may not see too many electronic circuits involved in common electric fans, as they just use coil winding in the motors. However, for a laptop or PC, we may see the kind of transformers that step down the main outlet, which is usually at $220 \mathrm{~V} \mathrm{AC}$, to the device's working voltage, for example, at 24V DC. Along with transformers, there is also a possibility of a switched-mode power supply. This different type of power supply may change the behavior of the induction voltage, which will be measured using RCD, as in Figure 3.

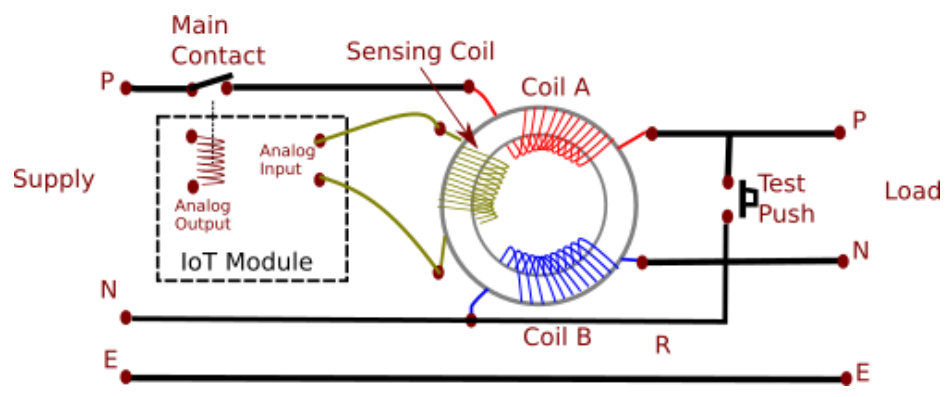

Figure 3 RCD core

As discussed above, one concern is that the RCD used as a sensor in this system might have its own characteristic in reading the leakage current in comparison with power meter. Since it will only obtain the induction voltage of the power line, this component may affect the relationship of the leakage with the power. It might have a nonlinear function corresponding to its induction voltage function, as shown in Equation 2.

$$
\operatorname{Load}_{\text {increase }}=\frac{\operatorname{Load}_{\text {final }}-\operatorname{Load}_{\text {initial }}}{\operatorname{Load}_{\text {initial }}}
$$


Equation 4 can be used to calculate the increasing power of the loads. It is trying to have a larger gap between one load and another.It will be useful later on in order to draw the relationship between the leakage current and power.

To test the circuit, three LED lamps with known power specifications are used. The lamps represent one kind from various types of loads, for example, electric fans, TV, and laptops. To bring about the leakage condition, we use a switch to bypass one of the RCD coils (Sutanto et al., 2019). A testing device is employed to test the load over normal and leakage current conditions. It is also identified via a gap of the induction voltage value at the sensing coil.

LED lamps are compared with CFL lamps in Latief et al. (2019), based onits DC characteristic, LED has been chosen in this experiment. The filter design for the RCD is initially described before giving an overview of our monitoring system with the discussed IoT system and Python server. The system is then evaluated with different kinds of loads by comparing the LED lamp as DC load and electric fan as an AC type. It is also tested with different loads using three different wattages of LED lamps. The results of these three loads would give us hint at the possibility of a higher range of load power, as thedesigned test in this system was only with real devices of $2-4 \mathrm{~W}$ gap in load's difference.

\section{Results and Discussion}

Using the system, it is possible to conduct a complete analysis starting from the hardware. This is continued with the leakage current from three LED lamps and tested over various loads to see the difference. Finally, the results from using machine learning with a binary classification of LED lamps are described.

\subsection{Hardware Analysis}

The IoT-based monitoring system described here can monitor a utility's leakage current via a smartphone using the Blynk application. The platform also sends the recorded data to the server. The hardware consists of a series of RCDs that can sense the leakage current from any device. The leakage current condition is simulated using a toggle switch. With this switch, it is possible to simulate normal and leakage currentcondition as the switch will bypassing the secondary coil in order to have maximum leakage current (Sutanto et al., 2019).

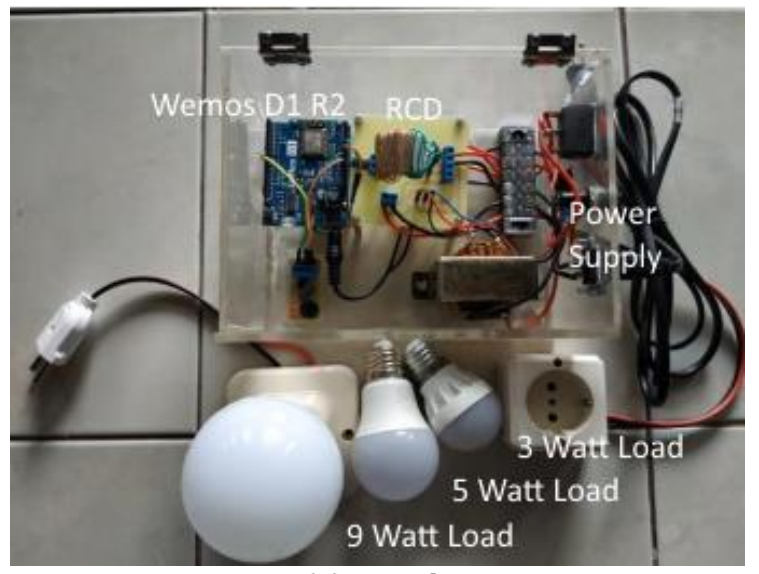

(a) Hardware

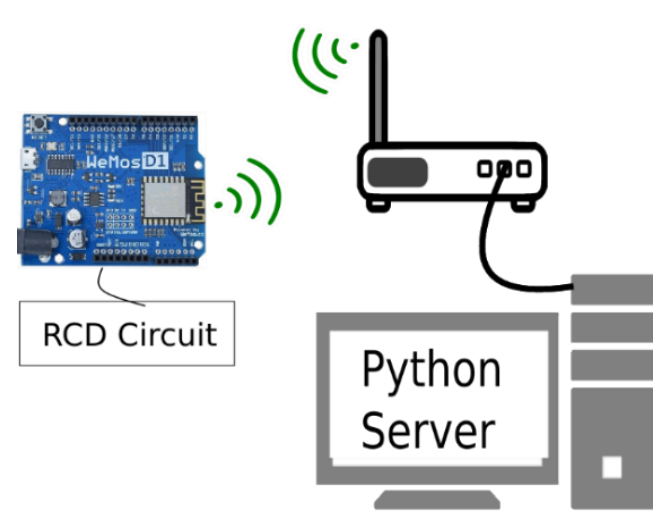

(b) Connection

Figure 4 IoT system hardware and connection

Figure 4 shows the hardware used in this experiment. It consists of three main partsthe WeMos D1-R2, RCD, and power supply. These parts are basically needed to make the 
IoT work. The WeMos D1-R2 is responsible for connecting to Wi-Fi and taking data from the RCD. Inside the RCD module, there is a filter module, as discussed above. This module converts the original AC signal to DC voltage to make sure it can be read by the WeMos. Finally, there is the power supply. This part provides electrical power consumption for the WeMos D1-R2. The proposed system with the Blynk framework has been tested in Sutanto et al. (2020). The connection between the hardware and the server is shown in the block diagram in Figure 4b. The data are collected at the server through the IoT system. Finally, the data analysis is carried out at the server by utilizing Python language. Python is supported by many libraries, making it useful for us to analyze the distribution of data.

\subsection{Leakage Currents from Three LED Lamps}

Three LED lamps were tested under normal and leakage current conditions, which may result in two different leakage current values. The tests used lamps with power loads of $3 \mathrm{~W}$, $5 \mathrm{~W}$, and 9W. Considering Equation 4, we can see that the loads increased by $66.67 \%$ and $80 \%$. The test was carried out practically by following the procedure of the described system. The first step was connecting the Blynk application with available Wi-Fi. Then, the two available conditions (normal and leakage current) were applied to each of lamps. Finally, we could use the generated data from the IoT platform for analysis. The values of one of the analyses from this leakage current monitoring tool were observed.

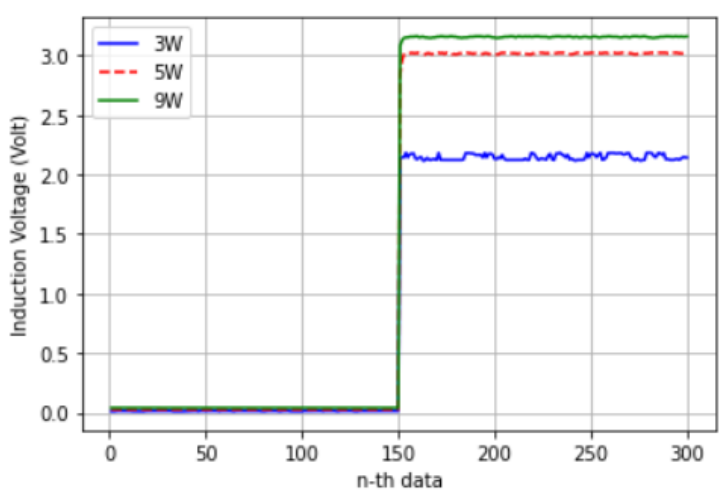

(a) Transition signal

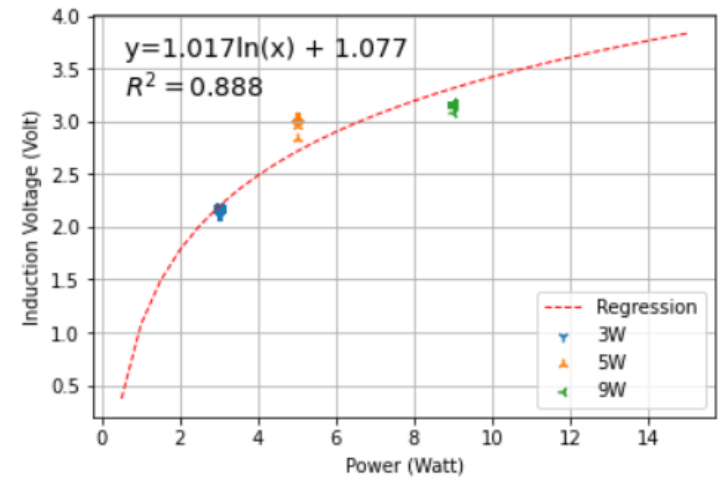

(b) Leakage trend line

Figure 5 Comparison of $3 \mathrm{~W}, 5 \mathrm{~W}$, and $9 \mathrm{~W}$ loads

Figure 5a shows the transition of each lamp from normal conditions to leakage current conditions. It shows how the values changed in these two conditions with a big gap. From the lamp with a $3 \mathrm{~W}$ load, the Blynk application recorded a stable value for induction voltage with values around $0.010-0.013 \mathrm{~V}$ with a gap of only about $3 \mathrm{mV}$ and an average value of $0.012 \mathrm{~V}$. After the state was changed to the leakage current, it recorded induction voltages at $2.119-2.184 \mathrm{~V}$, with a gap value of $65 \mathrm{~V}$ and average value of $2.150 \mathrm{~V}$. Similarly, for the $5 \mathrm{~W}$ load under normal conditions, the induction voltage was around $0.026 \mathrm{~V}$. Once converted into a leakage current state, the value increased a few times before staying at an average value of $3.019 \mathrm{~V}$, with a gap of around $13 \mathrm{mV}$. The range of steady values was $3.010-3.023 \mathrm{~V}$. At a load of $9 \mathrm{~W}$, a stable voltage was recorded at $0.039 \mathrm{~V}$ under normal conditions. Meanwhile, under leakage current conditions, the value also increased a few times before reaching a steady value at an average voltage of $3.157 \mathrm{~V}$, with change in gap of $15 \mathrm{mV}$, or values changing between $3.145 \mathrm{~V}$ and $3.161 \mathrm{~V}$. Overall, as shown in Figure $5 \mathrm{a}$, we could observe that the normal condition had a more stable and very small value. The value in the current measurement could be less than $1 \mathrm{~mA}$. Then, during leakage current conditions, the 3W LED lamp had the most data variation. 
The trend line with the best fit to the changes between the induction voltage versus power of our three LED lamps under the leakage current condition can be seen in Figure 5 b. The one-degree logarithmic equation could be fitted with $R^{2}=0.888$ at $y=1.017 \ln (x)+$ 1.077. This brings us to the reality of a non-linearity of that relationship because $R^{2}$ is the statistical parameter for measuring the closeness of the data to the regression line. To prove this, it is necessary to bring up more loads with a higher wattage.

\subsection{Testing of Various Loads}

As discussed above, it is necessary to continue this experiment using several other loads, such as those of mobile laptop, laptops, fans, and TVs. With this test, we included other types of loads. For example, a mobile laptop and laptop may have a power supply in DC type. In conducting this test, it might also be possible to determine the maximum power load that could be used in this IoT-based application.

Table 1 Test of various loads

\begin{tabular}{cccc}
\hline Load (Brand) & Power & Condition & Induction \\
\hline Mobile Laptop (Acer) & $40 \mathrm{~W}$ & Turn On & $2.87 \mathrm{~V}$ \\
& & Speed 1 & $1.97 \mathrm{~V}$ \\
Fan (Cosmos) & $50 \mathrm{~W}$ & Speed 2 & $2.02 \mathrm{~V}$ \\
& & Speed 3 & $2.04 \mathrm{~V}$ \\
Laptop (HP) & $65 \mathrm{~W}$ & Turn On & $2.97 \mathrm{~V}$ \\
TV (Polytron) & $80 \mathrm{~W}$ & Turn On & $3.15 \mathrm{~V}$ \\
\hline
\end{tabular}

Table 1 shows several types of loads with random brands of products. The only connection between these loads is that there is an increase in power. However, the power was intentionally left unmeasured. The power levels were only taken from the specification plates behind the devices. The average induced voltage during leakage current conditions was measured using Blynk. Here, the largest load was from the TV, with a rated power of $80 \mathrm{~W}$. This can still be read by our system with the average induced voltage generated by the RCD of $3.15 \mathrm{~V}$. However, not all values showed correlations with one another. For example, the notebook, with a power of $40 \mathrm{~W}$, showed a higher induction voltage of $2.87 \mathrm{~V}$ compared with the electric fan, which was only $2.04 \mathrm{~V}$ at most. Nevertheless, an increase in the induction value emerged when the comparison was run using typical loads, such as between the notebook at $40 \mathrm{~W}$ and laptop at $65 \mathrm{~W}$, which were $2.87 \mathrm{~V}$ and $2.97 \mathrm{~V}$, and among the electric fan values at different speeds, which were in the range of 1.97-2.04V. This result was similar to the results for the three LED lamps, which had values of $2.150 \mathrm{~V}, 3.019 \mathrm{~V}$, and $3.157 \mathrm{~V}$ for $3 \mathrm{~W}, 5 \mathrm{~W}$, and $9 \mathrm{~W}$, respectively. To investigate the reason for this, it is necessary to look at the waveform. This could explain why there was inconsistency from the data where the increasing power was not followed by increased induction voltage, as given in Table 1.

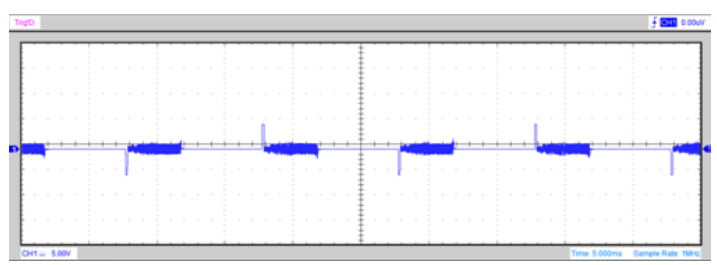

(a) LED lamp

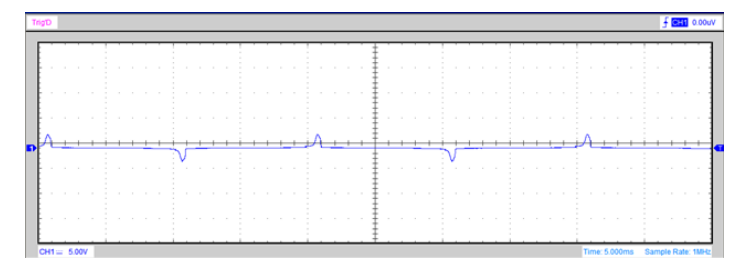

(b) Electric fan

Figure 6 Signal waveform before filter

Although the results at Table 1 showed that it could still successfully read a maximum power load of $80 \mathrm{~W}$, there was still a pattern which we needed to determine. Thus, we used 
an oscilloscope for observation by looking into one which had a range of values. They were LED lamps and electric fans, which had three different speeds. Figure 6 shows the induction voltage from RCD, which we can find as $\mathrm{V}_{1}$ if we looked back at Figure 1. From the figure, it can be seen that the waveforms of the lamp and electric fan were different. Unexpectedly, the lamp with a load of $5 \mathrm{~W}$ had a higher peak compared with the electric fan, which should have a peak of $50 \mathrm{~W}$. The only similarity was that both of them had a similar frequency, following the electricity main outlet, of $50 \mathrm{~Hz}$ :

$$
f_{p s}(t)=A \cdot \sin (\omega t)=220 \sin (100 \pi t)
$$

The original power line waveform had been changed from its common sinus function with a frequency of $50 \mathrm{~Hz}$, as expressed in Equation 5. Understanding the physics from Equation 2 and the differences at the load's power consumption, we can write this as Equation 6 by following the signal convolution, as in Roddy and McEwen (2020):

$$
I_{\text {leakage }}(t)=\left(f_{p s} * h_{\text {Load }}\right)(t)=\int_{-\infty}^{\infty} f_{p s}(\tau) \cdot h_{\text {Load }}(t-\tau) d(\tau)
$$

With $h_{\text {Load }}$ as the load's function, we were able to obtain a different Ileakage from each load circuit as its convolution with $f_{p s}$. This may be why we could only see the power line frequency at a glance from every induction load. There had been a transformation of the original power line signal to this leakage current at Equation 6 before obtaining the induction voltage using Equation 2, as shown in Figure 6.

Table 2 Before filtering

\begin{tabular}{ccccc}
\hline Load & Min. (V) & Max. (V) & RMS (V) & $\begin{array}{c}\text { FrEquation } \\
(\mathrm{Hz})\end{array}$ \\
\hline LED Lamp & -5.18 & 4.86 & 0.65 & $1,167.00$ \\
Electric Fan & -2.67 & 2.82 & 0.47 & 49.97 \\
\hline
\end{tabular}

From the oscilloscope data, we could gather the statistical data shown in Table 2 with its Root Mean Square (RMS) values. From this table, we can see that the LED lamp had a swing voltage, with an amplitude of around 5V. Meanwhile, the electric fan's amplitude was only around $2.7 \mathrm{~V}$. However, the oscilloscope could only see a frequency close to the power line frequency for the electric fan. The LED lamp was overcome with a high-frequency signal, which can be seen in Figure 6 as a horizontal bar of low voltage along the signal.

Table 3 After filtering

\begin{tabular}{ccccc}
\hline Load & Min. (V) & Max. (V) & RMS (V) & Vpp (V) \\
\hline LED Lamp & 3.01 & 3.02 & 3.02 & 0.09 \\
Electric Fan & 1.49 & 1.55 & 1.52 & 0.06 \\
\hline
\end{tabular}

If we continued with the capacitor filter, we could see a rectifying effect. The signals became steady DC signals, although they could have a ripple voltage as the Vpp, as shown in Table 3. The most ripples could be seen in the LED lamps, whereas the electric fan signal was more rectified. This again changed the voltage being read by the system, as discussed above in relation to Equation 1. The signal's peak to peak voltage was no longer an amplitude, as shown in Figure 7. 


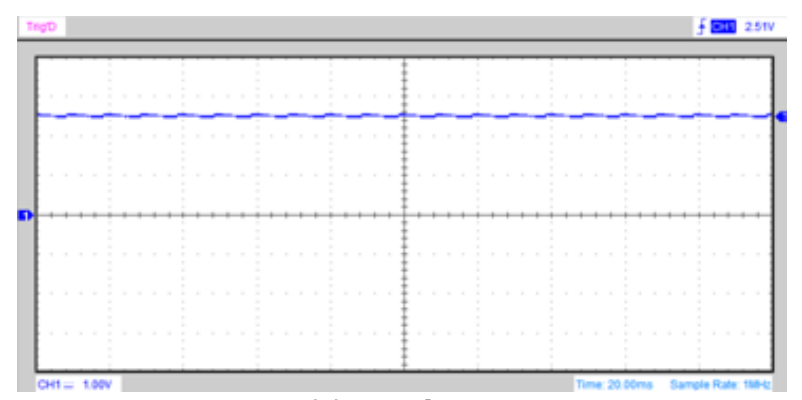

(a) LED lamp

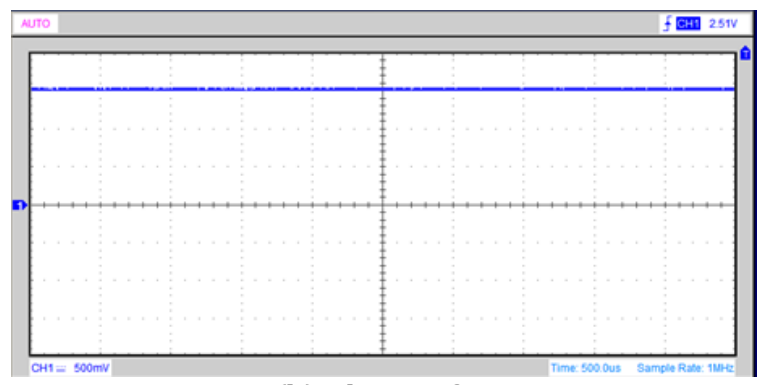

(b) Electric fan

Figure 7 Signal waveform after filtering

Figure 7 shows the signal after passing through the capacitor filter. This is the value that will be read by the microcontroller. By looking at these steps, it can be understood that the correlation of power to the induction voltage was not really close. It might be possible to see it as a leakage current signal. The leakage current might respond more to the residual power consumption over the load's circuit rather than the rated power consumption.

\subsection{Relationship based on Machine Learning}

Data gathered at the server via the Blynk application could be used as a dataset for machine learning. The data were employed for analysis of normal and leakage current conditions. Since we could obtain data from this IoT-based electric leakage current application, we would like to determine the difference between the cut offs of the various loads. To achieve this, training via a machine learning model was necessary. Determination of each condition was reevaluated by the server, which means that the limit to determine the conditions of normal and leakage currents could be adjusted. There might not be a specific limit, such as $1 \mathrm{~V}$, because the limit was determined by machine learning from time to time. This was possible because machine learning provides the ability to learn the data according to the adjusted behavior.

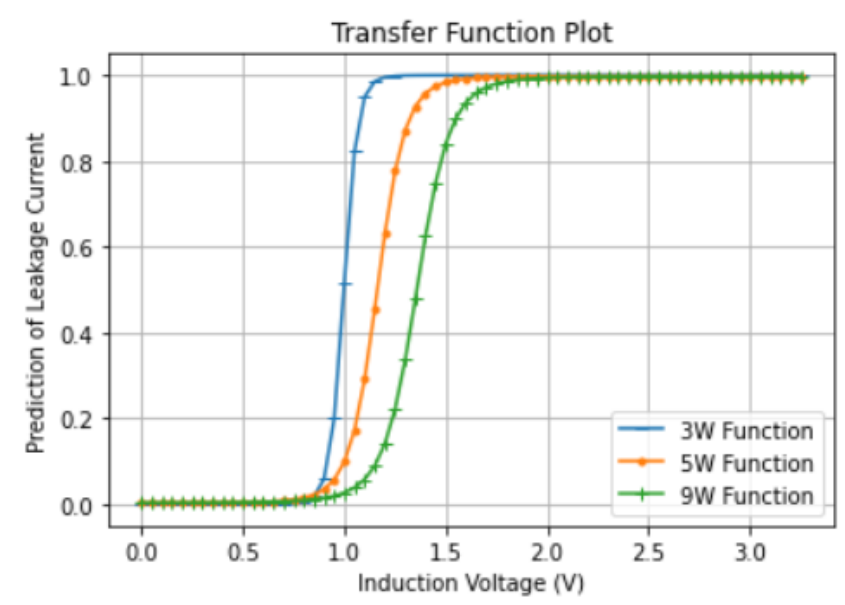

Figure 8 Transfer function

Figure 8 is a graph of the prediction of leakage current conditions from three LED lamps over the measured induction voltage. With a value of 1 representing leakage current condition and 0 representing normal conditions, predictions based on the induction voltages of $3 \mathrm{~W}, 5 \mathrm{~W}$, and $9 \mathrm{~W}$ lamps shifted slightly to higher range values. Using Equation 4 , it was found that the loads showed increases of $67 \%$ and $80 \%$; however, the induction voltages were only $19 \%$ and $16 \%$ with this machine learning model prediction. Overall, we 
could see that the transition values were around $1 \mathrm{~V}$. In a practical sense, it could be observed that there is a possibility to determine the medical equipment's leakage current in hospitals with this system because the induction voltage change exhibited a more than $10 \%$ increase. An improvement in the machine learning model will definitely also increase the gap.

\section{Conclusions}

Using a filtered RCD circuit, an IoT-based electric machine leakage learning application was developed to detect the leakage current in a new way. The output sensing coil was rectified using a capacitor circuit to be read by the WeMos D1-R2 module in a DC value. By utilizing the Blynk application, it was possible to monitor the induction's voltage from various loads.

The leakage current of various components only seems to have a relationship with the power consumption if used with similar types of loads. Thus, the correlation might be missed if the leakage current is compared with different kinds of loads. This issue was seen between the LED lamp and electric fan loads, and it was explained according to the waveforms of induction voltage signals.

We were able to use the gathered data for machine learning. With the employed technology, we could define the adjusted threshold voltage for the best transition from the normal condition over the leakage current condition. The demonstration was given by similar kinds of LED lamps with increasing loads of $3 \mathrm{~W}, 5 \mathrm{~W}$ and $9 \mathrm{~W}$. The results indicated that there should be a change in the cut-off point for each different load.

\section{References}

Bohora, B., Maharjan, S., Shrestha, B.R., 2016. IoT Based Smart Home using Blynk Framework. Zerone Scholar, Volume 1(1), pp. 26-30

Chong, S.S., Raman, A.A.B.A., Harun, S.W., Arof, H., 2016. Dye Concentrations Measurement using Mach-Xehner Interferometer Sensor and Modeled by ANFIS. IEEE Sensors Journal, Volume 16(22), pp. 8044-8050

Gupta, M., Sharma, V., 2019. Design and Simulate the Modified Circuits of Switched Capacitor Filter using Mentor Graphics Tool. In: $20193^{\text {rd }}$ International Conference on Recent Developments in Control, Automation \& Power Engineering (RDCAPE), pp. 431436. IEEE

Latief, Y., Berawi, M.A., Koesalamwardi, A.B., Sagita, L., Herzanita, A., 2019. Cost Optimum Design of a Tropical Near Zero Energy House (NZEH). International Journal of Technology, Volume 10(2), pp. 376-385

Lee, C.-H., Lin, S.-D., 2005. Safety Assessment of AC Earthing Systems in a DC TractionSupply Substation. IEEE Proceedings-Electric Power Applications, Volume 152(4), pp. 885-893

Muhammad Asraf, H., Nur Dalila, K.A., Zakiah, M.Y., Amar Faiz, Z.A., Nooritawati, M.T., 2018. Computer Assisted e-Laboratory using Labview and Internet-of-Things Platform as Teaching Aids in the Industrial Instrumentation Course. International Journal of Online and Biomedical Engineering (iJOE), Volume 14(12), pp. 26-42

Piponi, D., Moore, D., Dillon, J.V., 2020. Joint Distributions for TensorFlow Probability. arXiv preprint arXiv:2001.11819

Roddy, P.J., McEwen, J.D., 2020. Sifting Convolution on the Sphere. arXiv preprint arXiv:2007.12153 
Roy Chowdhury, A., Saha, B., Sarkar, G., Choudhary, J., Sahana, S., Singh, D., 2019. IoT Based Energy Meter Towards Efficient Power Consumption. Available at SSRN 3493056

Shukla, N., 2018. Machine Learning with TensorFlow. Manning Publications Co.,Shelter Island, New York, U.S.A

Sutanto, E., Ain, K., Aziz, M., Escrivá-Escrivá, G., 2019. A Study on DC Limit Parameters in RCD Operation using Capacitor. Journal of Engineering Science and Technology Review, Volume 12(4), pp. 7-14

Sutanto, E., Putra, T.S., Kuncahyojati, A., Agustin, E.I., 2020. IoT Based Electricity Leakage Current Monitoring using Blynk App. In: AIP Conference Proceedings, 2314, p. 040004

Wibisono, G., Firmansyah, T., Priambodo, P.S., Tamsir, A.S., Kurniawan, T.A., Fathoni, A.B., 2014. Multiband Bandpass Filter (BPF) based on Folded Dual Crossed Open Stubs. International Journal of Technology, Volume 5(1), pp. 32-39

Zulkifli, F.Y., Atmaja, A., Rahardjo, E.T., 2014. Implementation of Single Cell Composite RightLeft Handed Transmission Line for Ultra Wideband Bandpass Filter. International Journal of Technology, Volume 3(2), pp. 121-128 